\title{
On the Importance of the American Black Fraternity and Its Enlightenment for the Fellow Townsmen Association in Chinese Universities*
}

LI Rui

China Youth University of Political Studies, Beijing, China

\begin{abstract}
This paper first analyzes the benefits offered by the American Black Fraternities to the black college students in terms of improving academic achievement, cultivating leadership abilities, and enhancing social involvement on campus. Based on the successful experience of the American Black Fraternities, this paper further explores solutions to the serious problems existing in the Fellow Townsmen Association in Chinese universities to make it the same valuable asset for the development of the members' personality and comprehensive quality. The Association should be leveled up to an official student society to solve many of its managerial problems, and set a group goal to direct its members to the right track of serious study and completely transform the form and the content of its activities to improve the social skills of its members.
\end{abstract}

Keywords: Black Fraternity, Fellow Townsmen Association, socialization, academic achievement, leadership, campus engagement

\section{Introduction}

In America, many of black college students have negative experiences in predominantly white institutions, suffering lower GPA (Grade Point Average), higher dropout rates, less likelihood of enrollment in advanced degree programs, and poorer overall psychosocial adjustment. A great many black students are behind schedule, that is, they have fewer cumulative credit hours than the norm for their year in school, which finally results in longer years than the traditional four years to earn college degrees or no degrees at all. Compared to the total population, black students are nearly three times as likely to leave college for academic reasons. Due to the absence of a strong and relatively large core of black students on campus, many black students feel that they do not fit in, and some even feel socially isolated. They often lack the kinds of meaningful interpersonal relationships that foster academic and career achievement. They are longing to be affiliated with groups that respond directly to black students' needs and concerns. They must "find constructive means of encouraging helpful peer contact rather than mutual avoidance" (Fleming, 1983, p. 156).

\footnotetext{
* Acknowledgements: This 2015 project is subsidized by China Youth University of Political Studies (No. 189070824). LI Rui, lecturer, M.A., Foreign Language Department, China Youth University of Political Studies.
} 
The Black Fraternities offer a platform through which to address black issues and connect with other black students. They are "some kind of organizations to protect the black students' interests, and to afford some systematic means of providing wholesome recreation and social pleasures" (Crump, 1983, p. 19). So they are among the most popular even the primary out-of-class engagement venues for contemporary black undergraduates. They serve as a much-needed source of social support, a haven from the racism, isolation, and under-representation that black students often experience. They stress the importance of academic success, and provide opportunities for leadership development. They sponsor most of the culturally-appealing social activities and provide unusually rich out-of-class learning and personal development opportunities for the black students. They afford their members chances to develop valued cross-cultural communication skills and enable them to learn from others who are racially different. The black students will first consider joining them before branching out to mainstream and majority white groups.

\section{Black Fraternity and Academic Achievement}

Being involved in a network with a strong academic orientation is very important to academic success. The Black Fraternities are supportive of the intellectual mission. They all identify academic excellence as a core value and each group tries to get a satisfactory position in the all-Greek academic standings report at the end of each semester. Most groups fear being suspended or placed on probation by their national headquarters because of poor academic performance, and the members recognize that individual grades will impact the overall academic vitality of the entire group. They are aware that what they do in their classes, including participating actively, will affect the performance of the whole group. In Whipple, Beier, and Grady's (1991) research, they found that black students who joined fraternities had a strong orientation to academic life and high levels of academic involvement. What is more, the members think they have a responsibility to be good role models for other black students in class, and to positively portray the group. Since some of their non-Greek peers perceived them to be party animals and hazers, they work harder in their classes to show that the Black Fraternities are comprised of smart and thoughtful members who are serious about academics.

\section{Black Fraternity and Leadership Development}

Leadership is one of the positive qualities associated with or attributed to membership in a Black Fraternity. Many of the black students may perceive or experience difficulty in attaining leadership positions in departmental groups, clubs, and campus student organizations. The Black Fraternities provide the black students with more and earlier developmental opportunities to practice leadership-related skills and acquire stronger leadership abilities than do White-dominated student groups, thus alleviate the black students' feelings of powerlessness and isolation in the larger campus community. The broad scope of Black Fraternity activities provides members with a range of leadership skills development opportunities through involvement in community service planning, campus programming, and social events. Black students who are involved in Black Fraternities are more likely to experience higher degrees of leadership development, perceive the value of leadership skills more positively and demonstrate a generally higher level of confidence in their abilities to perform several leadership-related skills than are uninvolved and unaffiliated students. Early leadership experiences provide the black students with the tools they need to succeed academically, in the workforce, and in 
other social arenas. The most important value of leadership experiences is that it helps them to feel better about themselves and consequently become better people.

\section{Black Fraternity and Engagement in Campus Activities}

As Strange (1986) pointed out, the Greek system is a powerful vehicle for socialization. Membership in a Black Fraternity is directly related to black students' social involvement. Frequent participants in Black Fraternity activities are in fact highly involved in general campus life. They increase their overall participation in other activities and organizations outside of their fraternities to a significant degree. Greater social involvement brings greater gains in general cognitive abilities and increased tolerance for racial and ethnic differences through the interaction with people from different racial, ethnic, and cultural backgrounds. Meanwhile, it prolongs the black student's persistence in college since the latter totally depends upon the degree to which students are integrated within the college social and academic systems. The black students accumulate a lot of interpersonal skills through their involvement in the Black Fraternity and use them as the basis to create and maintain favorable social relationships with blacks and whites, faculty and students, on the campus.

\section{Enlightenment on Fellow Townsmen Association in Chinese Universities}

The American Black Fraternities provide service and fellowship opportunities for the black students and promote their professional achievement through higher education. They take seriously their role in promoting members' achievement and success and are beneficial both socially and developmentally. Therefore, they are assets to the campus community. The Fellow Townsmen Association in Chinese universities can learn a lot from the Black Fraternities and undergo fundamental self-transformation to better serve the needs of its members.

Fellow Townsmen Association (hereafter referred to as Association) in Chinese universities is an unofficial student association comprising students from the same geographical region. It is the result of the cultivation of Chinese unique hometown binding and traditional culture. The Association is a typical peer group and exerts enormous influence on the students' life and development. American scholar Mead (1988) said, "the influence of peer group is big enough to change the traditional way of culture transmission in today's society" (p. 51). In order to strengthen the positive effects of the Association and make it helpful for its members' study and character development, several measures should be taken to radically reform it.

\section{Transforming the Essence of the Association}

In Chinese universities, the Association is a secondary student society with a series of managerial problems. There are no formal rules and regulations to follow, and no explicit rights and obligations for the members who gather together spontaneously out of their love and longing of the hometown. All the operations are done according to the unwritten common practice, which leads to blindness and arbitrariness. For instance, the collection of the membership fees is often chaotic due to the lack of a fixed person in charge, and most members are left unknown about how the money is spent. Whenever an activity is going to be organized, the members simply have a rough division of responsibility, which greatly reduces the efficiency. What is worse, the low efficiency often results in huge waste of money, which naturally increases the economic burden of the members. Besides, there is no election at expiration of office terms. Such loose management can only bring about the slackness of the group. 
Therefore, in order to fundamentally regulate the operation of the Association, it is imperative to promote its status and turn it into an official student society. The universities can treat various Associations on campus as a special student society with each Association as a branch and supervise its activities according to the "Regulations of the Association Management" which should be laid down beforehand. The student affairs department should guide the direction of the Association activities and regulate its management comprehensively from the perspective of founding condition, organizational structure, daily operation, supervisory management, check and evaluation, and alteration and dismission.

The Association should establish a distinctive managerial pattern, and draw up a set of rules and regulations in accordance with its own characteristics to make the management more effective and better organized. Such regulations should combine with those of the universities for student societies, and cover all the activities of the Association. The Association can also use the rules and managerial mode of other student organizations for reference, but it is paramount to create its own system which is permitted by the universities. The leader of the Association should be elected through formal procedures among candidates with high reputation and strong organizing and coordinating abilities, and several management branches should be set up to clearly divide responsibilities. An exclusive bank account is to be introduced and the financial situation should be revealed periodically to improve the transparency of expenses. The budget for each activity is needed to work out the plan of spending, and a summary afterwards is necessary to learn from the experiences and try to avoid any kind of waste.

After the Association becomes an official student society, more fixed managerial positions will be set up to improve its organizational structure and bring its function into full play. Besides the person in charge of finance, there should also be people responsible for planning and publicity, and the planners should consist of students from all the schools or departments of the university in order to better interact with the members of different majors and allocate the work more effectively. The increase of the administrative positions provides the members with more opportunities to participate in the social practice, exercise leadership, and realize their self-value. Most of the university students were once the excellent ones while in senior high schools. After they come to the university, they find a large number of students who are as brilliant as they are or even better, so they suddenly become average and have few opportunities to present themselves. However, they still long for the recognition from others and aspire to develop and exhibit their comprehensive skills through group activities. The Association can ideally satisfy their needs when it becomes official and create more positions for its members to demonstrate and sharpen their skills, especially the leadership. In addition, the Association will be able to make use of the places that are exclusively offered to official student societies to carry out activities; thereby the members can get rid of the routine practice of going to restaurants or ballrooms for gatherings.

\section{Transforming the Goal of the Association}

The main social and developmental task for university students should always be study, that is, study as the basis of the personal growth. Individual's study depends on self-planning, self-endeavor, and self-independence, but it is, at the same time, greatly influenced by the campus atmosphere, especially the student societies that one takes part in. An educator claims, "The truly valuable thing for young people is the surrounding environment" (quoted in ZHAO, 1992, p. 39). Chinese scholars also found through their researches in recent years that the value 
choice of Chinese youth is always closely connected with other people and particular situation, and the concept of "individual" and "self" is often mutually dependant on groups or other people (XU \& ZHENG, 2007). Young people tend to adopt the standards of peers when faced with the contradictory influence coming from grown-ups and peers, which will easily lead to the blind conformity behavior of the university students. At present, it is common to see members of the Association indulge in eating, drinking, and pleasure-seeking together, and the passive slogans like "cramming for exams is enough" and "playing hard rather than studying hard" are circulated among members. In order to reverse such sloppy and undisciplined trend, a group goal of studying hard should be set to guide the members to the right track of improving their study. The group cohesion can be very helpful in achieving the goal. The stronger the cohesion is, the more powerful the Association's influence is.

Firstly, the student society management department of the university can rank all the Associations on campus according to the average GPA of their members, and lay down the rules of reward, thereby to urge each Association to set a group goal of improving the overall study level of its members. When the group goal is in accordance with the individual's needs and hopes, the group activities can be effectively carried out and the individual's comprehensive development can be greatly promoted. After the group goal is settled, the common psychology of the Association will make the members adjust their behavior and keep up with the group. That is to say, the members will pay more attention to their study so as to improve the group's reputation and protect its interest. Hence, the initiatives of the members are aroused, and they are encouraged to take the responsibility of boosting the healthy development of the Association.

Secondly, since the Association has the unique characteristic of the conductor of message dissemination, it can be properly used to help freshmen shorten the period of adaptation to the new environment, correct their study attitude, and improve their study as soon as possible by introducing the information about the faculties and facilities of the university, features of various majors, the study methods, the exam regulations, the career prospects, the living habits, as well as experience of personal relationship. Due to the similar educational background and growing experience, members are easy to strike a chord with each other, which can strengthen the effects of the flow of information. The fact that the members are coming from different departments, grades, and classes gives them the privilege of absorbing various kinds of knowledge and experience, through which they can explore a set of study methods and work guidance that are suitable for themselves. In addition, the Association can advocate study teams among members to help them realize their inadequacies and improve them timely with the help of other members. In the Association, every student will subconsciously compare him or herself with others and realize the differences. Under such equal circumstances, it is much easier for them to objectively evaluate themselves and find their positions in the group, through which they can naturally learn self-education.

Finally, the core members of the Association should become good samples for other members, and try to create an atmosphere of competing with others, learning from others, catching up with others, helping others, and surpassing others within the group, thus help adjust the value choice of the Association to the right direction. The core members are always in the leading position, whose behaviors affect the existence and development of the whole group. They have great inspiring and appealing power, and their study attitude, way of thinking and acting are obviously seen to have gradual effects on other members. So the core members are supposed to study hard and set examples for others so as to call on all the other members to improve their study. 


\section{Transforming the Form and the Content of the Association's Activities}

Currently, the activities of the Association are held quite casually without serious plans and focuses. The content of the activities is nothing but having dinners together or going to karaoke bars, which has no educational significance. So it is crucial for the Association to vary the forms of its activities and promote the level of content. Under the guidance of the instructors and teachers in charge of the student societies, the Association should carry out activities that can promote the solidary and friendly relationship among members and activities than are rich in elements of science and technology as well as culture. The Association should encourage its members to actively take part in various activities held by the Association or on campus to cultivate their social abilities, quicken the process of socialization, and then ultimately improve their comprehensive quality.

The Association can enrich the extracurricular activities by periodically carrying out cultural entertainment activities, voluntary services, athletic competitions, like having football, basketball, or volleyball matches with other Associations. It can also organize a series of academic lectures and knowledge contests, or arrange technological service for its members in which the members can practice their skills, enhance their self-confidence, and promote their all-round development. What is more, the Association can actively advocate such environmental protection idea as saving water and electricity, planting trees, and taking good care of the campus environment by taking advantage of its network. It can also aim at creating brand activities to raise the members' awareness of social responsibility, like the brand activity of serving the left-behind children, teaching voluntarily in the poor mountain area, etc.

The Association can hold folk customs and culture festival on campus through cooperation with the student union of the university and other student societies, exhibiting different local traditions and facilitating cultural communication across regions. The members can not only take such opportunity to enjoy the familiar hometown atmosphere, and introduce their beloved hometown to other students, but also have a chance to get to know the colorful life and different practices outside their hometown, which broadens their horizon, expands their knowledge, and eliminates the prejudices caused by the stereotype based on different cultural background. The socialization of the university students requires their active involvement in the school life and continuous learning from the students with different regional culture. Moreover, each Association can sell the special local products during the festival, which can both satisfy the needs of the students on campus and create channels and accumulate experience for its members to become self-employed in the future.

\section{Conclusion}

The American Black Fraternities offer venues through which the voices of black college students can be shared and their needs can be addressed. The membership makes the black students competitive academically, brings leadership opportunities which they might not otherwise receive in the White-dominated organizations, and increases the level of their social involvement on campus. The Fellow Townsmen Association in Chinese universities which bears the same significance to Chinese college students should learn from the advanced experience of the Black Fraternity and carry out crucial reforms to truly become beneficial for the overall personal development of its members. 


\section{References}

Crump, W. L. (1983). The story of Kappa Alpha Psi. Philadelphia: Kappa Alpha Psi Fraternity.

Fleming, J. (1983). Blacks in college. San Francisco: Jossey-Bass.

Mead, M. (1988). Culture and commitment. Shijiazhuang: He Bei Renmin Press.

Strange, C. (1986). Greek affiliation and goals of the academy: A commentary. Journal of College Student Personnel, 27, 519-523. Whipple, E., Baier, J., \& Grady, D. (1991). A comparison of Black and White Greeks at a predominantly White university. NASPA Journal, 28(2), 140-148.

XU, R., \& ZHENG, S. (2007). College student organization and management suggestions. Journal of Shiyan Profession and Technology Academy, 6(3), 30-32.

ZHAO, X. L. (1992). Translation compilation of foreign educators (Vol. 3). Shanghai: Shanghai Education Press. 